\title{
NATURE AND THE CITY: A CO-EVOLUTIONARY PROJECT
}

\author{
Samir YOUNÉS \\ School of Architecture, University of Notre Dame, \\ 110 Bond Hall, Notre Dame, Indiana, 46556, USA \\ E-mail: samir.younes.1@nd.edu
}

Received 06 May 2014; accepted 16 September 2014

\begin{abstract}
Architects who understand the need to build enduringly are faced with the almost complete absence of international agreements with respect to a planetary ecological project. The coming environmental changes will probably occur long before the small measures that can be implemented by some building industries on a regional level have even the slightest effect. Meanwhile, the health of the planet in positive feedback. Any project that aims for a wise ecological dwelling on this planet needs to consider short-term sustainable measures in comparison with long-term enduring practices. Might schools of thoughts such as traditional architecture, Gaia theory, Earth System Science, deep ecology, eco-feminism, converge on a co-evolutionary partnership between the natural and the human?
\end{abstract}

Keywords: architecture and sustainability, ecology and building industry, environmental ethics, Gaia Theory.

\section{Introduction}

There is something hopeful about the current sense of urgency to build enduringly because it is a part of a larger consciousness seeking to establish an enduring civilization in cooperation with Nature. At the same time, there is something quite unsettling about the ever-growing severity of the Earth's health problems. What is hopeful, with respect to building activity, is the determined effort on the part of some architects and builders to seek ways to redress detrimental building practices on ecological and urban levels. What is unsettling is that good building practices, when and if they will occur on a scale significant enough to improve the ecology, will have to be realized while the Earth's health is in positive feedback - a condition where new developments or new problems serve to amplify or worsen an already critical state. Surpassing their most dire predictions scientists sounded an alarm, in 2008, because an acute level of 350 ppm (parts per million of carbon dioxide) had been reached, and declared that we could not have a planet "similar to the one on which civilization developed and on which life on earth is adapted" (McKibben
2010). At the time of this writing, the ppm level stands at 391 . To put the question differently, even if architects and builders all over the world were to suddenly agree on building enduring cities with natural materials and a minimal environmental impact - an unlikely possibility in the short term - the effects on the Earth for the foreseeable future are quite uncertain. On a broader scale, even if all governments in the world were to agree on the most ecological practices in building, agriculture, economic cooperation, energy resources and their consumption - an extremely unlikely possibility - the effects on the Earth for the foreseeable future are completely uncertain. For architects, enduring buildings is the immediate goal and enduring cities is the wider goal. For all of humankind, an enduring ecology is the broadest possible existential goal. For the Earth, to endure is an ultimate existential goal.

Those whose professional occupations, such as architects, directly affect the health of the Earth, and whose moral consciousness lead them to uphold the Common Good, usually make the following assumptions. They rightly assume that their field plays its part 
within the larger planetary ecology, and to the best of their abilities they bring their professional field into alignment with the larger scientific perspectives regarding the health of the Earth. Ultimately, they hope that if all the professions that affect the ecology were to be so aligned then they will additively result in a salutary outcome for planetary life. This is a vision of dedication and discipline with noble aims. Yet, this vision must be measured with respect to short-term and long-term effects because even if every country on Earth were to simultaneously begin implementing sound ecological practices tomorrow, it will take the Earth many centuries to respond to these new practices. Furthermore, notwithstanding the valiant efforts of environmentalists, there is little evidence that immense economic powers can be compelled to act for the human common good or for the good of the planet and all her species - powers that take from nature without adding back to nature, powers that commodify nature as if she were a consumable item, powers that corporatize nature and privatize water, powers that register patents on the seeds that nature makes while genetically modifying these seeds to self-destruct after only one harvest (Shiva 2005, 2010). Meanwhile, over the next few decades, many imminent and massive changes in the Earth's physiology are likely to occur long before good ecological practices and building practices take hold, that is, if they do at all.

With that in mind, we have little choice but to direct our efforts in order to escape from, to reduce, or to alleviate geological and climatic effects which are likely to be catastrophic. We may work on a sustainable retreat in the short term, and on enduring strategies for the long-term ${ }^{1}$. Architects who understand the need to situate building cities within a broader ecological project need to realize that a building with reduced carbon footprint, no matter whether it received a favorable rating from a professional organization, is itself a way to measure a sustainable retreat on a very small scale and with very short-term effects. But irrespective of the merits of such strategies, whether they are merely sustainable (in the short term) or truly enduring (over the long term), architects, especially traditional architects, need to consider two important questions. First, building cities that endure is a long-term ecological necessity that requires continuous global efforts across centuries in spite of difficult odds and considerable risks inside an unhealthy ecology. Second, in spite of our deeply engrained anthropocentrism, it is the Earth's evolution and time scale that sets the measure for human evol-

\footnotetext{
1 The expression sustainable retreat has been coined by James Lovelock.
}

ution and time scale and not the reverse. The effects of building enduringly will be seen centuries after the lifetimes of those who are presently initiating a project of long-term enduringness.

\section{Gaia and Earth system science}

In a rare public lecture, in the early nineteen seventies, Neil Armstrong discussed an important idea that derived from a powerful image that had an indelible effect on his psyche: the Earth seen from space. As all maps had hitherto displayed, the Earth's geography was divided by border lines that separated individual states. But in the unforgettable images from 1969, there were no boundaries between nations when one looked at the Earth from space. Earth does not come with national boundaries; it is one whole. Also in the early 1970s, scientists James Lovelock and Lynn Margulis formulated the Gaia Hypothesis which postulated that life on Earth kept the conditions on the surface favorable for all its organisms. The Gaia Hypothesis, in the beginning, did not enjoy widespread acceptance from the larger scientific community, because that community conceived of and studied the biosphere and the geo-sphere as if they were two separate realms. Indeed, humankind, although considered as part of the evolution of organisms, was considered as quasi-autonomous from that evolution. Much of the scientific outlook considered the Earth from an anthropocentric point of view, rather than a geocentric point of view. But since that time those who formulated the Gaia Hypothesis and the larger scientific community have come remarkably close, contributing to a broad ecological consciousness that culminated in important convergences such as the United Nations' Earth Summit in Rio di Janeiro in 1992, the Amsterdam Declaration of 2001, the declaration for the rights of Nature adopted by the United Nations, following a resolution introduced by Bolivia on Earth Day the 21st of April, 20112.

Many earth scientists, biologists, climatologists who were quite dissatisfied with the fragmentary approaches to studying the Earth eventually formulated Earth System Science which attempts to unify approaches to the life sciences and the earth sciences.

\footnotetext{
2 A worldwide movement of indigenous peoples has been working on developing national and international laws designed not only to protect ecosystems, but also to prevent their destruction under current perfectly legal business practices. Ecuador was the first country, in 2008, to change its constitution to include rights for nature to thrive and evolve. Faced with the risks from "gas-fracking", in 2010, Pittsburgh was the first American city to recognize the rights of nature and community above the business rights of corporations.
} 
These scientists came to prefer the study of the Earth in as interconnected a way as possible; but more importantly, they came to the conclusion that the Earth self-regulates its climate, its chemistry, its overall physiology. In turn, the Gaia Hypothesis evolved into the Gaia Theory according to which the Earth and the totality of life on it - the geology, the climate, the species - are one system kept together by one goal: the maintenance and the regulation of favorable surface conditions. The difference between Gaia Theory and Earth System Science is precisely that Gaia Theory sees the Earth as a self-regulating organism with a goal (Loveloc 1979, 2006: 15-47, 2009; Margulis1998; Intergovernmental... 2001; Kump et al. 2004). Both Gaia Theory and Earth System Science are less anthropocentric and more geocentric. The evidence that the Earth is one living system is being gradually accepted.

If we are a part of Gaia, albeit a problematic part, then we are also a part of Gaia's evolutionary goals. And one of Gaia's evolutionary goals, it seems, is to endure on its own scale and time. These goals occasionally require the disappearance, or the reduction, of some species for the sake of the larger whole. Difficult though it is for us to accept, it is quite possible for Gaia to reduce our numbers in order for it to endure. Geological records show that humankind has survived about seven catastrophic global conditions over the past one million years - some of these events were accompanied with a rise in sea levels of up to one hundred twenty meters. In our attempts at understanding the Earth, we consider the Earth anthropomorphically. This is inevitable, and sometimes a useful approach. If we are a part of the Earth, then it stands to reason to consider our relationship to the Earth as a whole. To put it in terms of the Great Chain of Being, we are a part relating to a whole. This is the overarching concept of symmetria that animated most of the world's architecture for millennia, but whose applications transcend architectural composition and apply to the relationship between species, and between species and the whole ecosystem, indeed between the planets and the solar system and beyond ${ }^{3}$. To understand ourselves and the effects of our collective actions, is to understand the Earth to a smaller degree, and in the process we have tended to anthropomorphize natural laws and natural products. But being anthropomorphic is different from being anthropocentric. The big problem with anthropocentrism is the flawed belief that the Earth exists for

\footnotetext{
3 The Prince of Wales' recent book Harmony, Harper Collins, 2010 , is dedicated to this very idea.
}

the central benefit of humankind above all else. Such a belief not only makes us treat Earth as if she was an inanimate set of forces and products, but it also blinds us to the Earth's reactions to events of our causing.

In moral judgment we consider egocentrism to be the worst isolationist and selfish conduct for an individual. The life of cities and nations compelled us to transcend egocentrism in favor of ethnocentrism, but we have also seen that ethnocentrism is ultimately a collective egocentrism. Finally, the increasing interconnectedness of the human condition in relation to all other lives on the planet led to the broadest expansion of consciousness to be collectively experienced: all centrisms are fragmentary and limited. But if there is a centrism to be had today, one that is useful for all, then let it be an Earth-centric view. We have passed then from being ego-centric, to being tribal-centric, to being city-centric, to being ethno-centric, and then Earth-centric. For those who are Earth-centric, the Common Good literally implies all of life on this planet, and this view is frequently in conflict with the nationalistic view of the world. In violently opposing the nation-centric and the Earth-centric views, maintains philosopher Ken Wilber, we oppose the national Ego to the world Eco.

In the age of colonialism, the resources of one nation were taken by other more powerful nations. As an extension of the first colonialism, the age of economic colonialism also sees the resources of one nation continue to be taken by more powerful nations or multinational corporations, a corporate world order as it were. We have treated the Earth with a kind of geo-colonialism. And how odd it is for us to keep speaking of sustainability, on the one hand, while dealing with the Earth as if we are an imperial power, on the other.

\section{The health of the Earth versus the state's interest}

In order to re-direct, or correct, our ways of dwelling on this planet in a sustainable way and then eventually in an enduring way, we need to know the Earth's state of health and then come to agreements about how to adapt to the Earth's conditions. Global warming, or in the words of Lovelock: global heating, constitutes the most evident manifestation of the planet's health. The Earth has fever. Scientists whose occupation it is to study the Earth's health, the geo-physicians as it were, can be divided into two groups. One group thinks that the damage we have inflicted on the Earth is very severe, while the second group thinks that the first group underestimates the gravity of the situation. Most, however, agree that the Earth's response to the 
effects of human damage is at this point irreversible. Not only may it be too late to stop global warming, but it may be too to late to delay it, much less reverse it. This is because many of our interventions around the Earth, at present, simply add to the Earth's ill health, which is in positive feedback. Hopeful realists that we are, we must learn to live inside the consequences that we have set in motion. This is not an emotional way of declaring nostra culpa. We did not always set to intentionally harm the Earth and cause catastrophic climatic conditions, but we did. The Earth has passed through several stages of heating and cooling, (glaciation, inter-glaciation, and warming) but the difference with the imminent heating this time is that it is humankind that caused it, with the most extreme conditions occurring over the past two hundred years. "We are the first species to become a geo-physical force, said Edward O. Wilson, altering Earth's climate, a role previously reserved to tectonics, sun flares, and glacial cycles. We are also the greatest destroyer of life since the ten-kilometer-wide meteorite that landed near Yucatán and ended the Age of Reptiles sixty-five million years ago" (Wilson 1998: 304-305).

In the view of many earth scientists, the right time to have begun worldwide efforts that would have eventually yielded noticeable ecological improvements today, would have been three or four centuries ago, or more (Millenium... 2005). At that time, of course, the necessary global knowledge was not available; and there were only one billion inhabitants of the Earth as opposed to almost seven billion today. More critically, the most extensive damage to the bio-sphere and the geo-sphere had not yet occurred. According to the IPCC (Intergovernmental Panel on Climate Change) reports of 2001, 2005, and 2007, the Earth's temperature is likely to rise by six degrees Celsius by the end of the 21 st century. Other scientific observers, who do not work for governments, believe that this will happen much earlier because these scientists regularly find that their observations of global heating are 1.3 or 1.6 time more severe than the predictions of IPCC. In 2007, all scientific observers were devastatingly surprised to find that $60 \%$ of the Arctic Ocean had melted in the summer, and although the melting was less severe in 2008, the remaining ice lost one and a half feet. None of this was predicted by their computer models, as most forecasts predicted this meltdown to occur by the year 2050 following the preferred narrative that governments wish to entertain; and that narrative states that the Earth is undergoing a steady and gradual increase in temperature and that it will attain a critical point conveniently timed at the end of the twenty first century.
The rise in sea levels remains the most reliable way to measure the rise in the Earth's temperature. Within a very short period of time, fifteen to thirty years according to some scientists, that is by the middle of the century, present levels of global heating will not only increase, it is likely that they will double, and this means, as we all know, that the sea that will replace the polar ice will absorb the temperature from the sun's rays, heat up and then expand. The resulting rise in the oceans will no doubt be considerable. Many countries (e.g. Bangladesh, the Netherlands), many cities (e.g. Venice, London, Tokyo, N.Y.), much arable land, will likely be under water. In large areas of the world, intolerable heat will be accompanied with a scarcity of food and water forcing many millions to migrate to cooler regions. In addition to economic immigration there will also be climatic immigration. In addition to the threat to humanity posed by climate change there will also be the threat of humanity against humanity as we battle for resources. Already we see the climate of the North African Sahara moving in strength into Southern Italy and Southern Spain. But we fall under the spell of a big illusion when we consider present conditions to be benign in comparison to dire climatic projections that have not yet happened. Doubting the severity of climatic conditions produces climate-change deniers which in turn reinforce shortterm policies of "business as usual".

Of course, the exact effects of the impending global changes are not determined with absolute assurance, and the best scientists admit that their most educated predictions can be wrong. Indeed the best scientists admit that despite their direct measuring of the changes to the Earth's temperature whether in the field or in modeled predictions in the laboratory, they are constantly being surprised by how they have underestimated the Earth's conditions. But because most of us are anthropocentric, we tend to focus much more on our own effects on the Earth, and we neglect the Earth's own response which is likely to be more formidable than we think. Amongst us, scientists may be the most prepared and knowledgeable about the Earth's conditions, but they have been candidly stating that they know little about how the entire biosphere will adapt to what may be an imminent global climatic change. Scientists agree that we cannot stop the imminent climatic change. They only disagree on the speed at which it may occur. We can, with international agreements, when and if they are possible, provide slight ameliorations on certain local levels. This has given rise to many scientific suggestions to alleviate local conditions; some of which are a bit fanciful, such as placing a large sunshade measuring several miles at the Lagrange points 
between the Earth and the moon, or burying large quantities of charcoal in order to absorb the carbon dioxide from the air. Modeled after the effects of volcanic eruptions on the atmosphere, where large quantities of floating particles of sulfur dioxide reflect the sun's rays back into space, the Chinese government experimented with injecting particles of sulfur dioxide into the atmosphere during the recent Olympic games.

But international agreements are frequently derailed by powerful nations and by multi-national corporations who consider their interests far above the interest of all. The Copenhagen climate talks in December 2009, were derailed by powerful industrialized nations who did not wish to sign a legally binding agreement that sets limits on greenhouse emissions, as required by the Kyoto Protocol. The failure to agree on binding commitments at Copenhagen was a moment of deep disappointment for those who entertained a slight hope that the world might unite and coordinate efforts in the face of overwhelming natural responses to effects of human causation. Powerful industrialized nations and corporations told poorer nations that they can either accept some non-binding general terminology of "voluntary goals" that every country can set for itself, or nothing at all. Most poor nations took the "nothing at all"4.

Many minds have been more focused on the present economic crisis and many minds have temporarily lost sight of the impending climatic crisis. In the process, economy and climate have been artificially separated. Leaders in the recent G20 summit in Toronto, in June 2010, agreed to cut their economies' deficits -some of them, like the U.S., wishing to cut their deficits by an astonishing half by the year 2013! Circumventing the United Nations, the G20 summit concerned the G20 economies and not the planetary economy or the planetary ecology. Yet the G20 did not produce any agreement on the banking practices that caused the world economies to shake to their very foundations, nor did they diminish in any way their subsidies for massive corporations that exploit massive amounts of fossil fuels. In a peculiar way, the thinking behind the G20's economic outlook operates as if the environment and the fate of the species are not an economic consideration. Most glaringly, the trillion dollar subsidies paid yearly to the fossil fuel industry was not even a consideration during the failed Rio + 20 summit in June 2012 .

\footnotetext{
4 Incidentally, when Bolivia refused to sign the accord, its promised aid funds were denied. However, Bolivia's efforts at achieving binding international agreements were slightly advanced in July of 2010 when it successfully convinced the United Nations to consider water and sanitation as a human right.
}

Facing global risks requires global coordination, hence global agreements. The coming environmental changes, some say imminent environmental catastrophes, will probably reach us long before the small measures that we can implement in the building industry for the next two or three of decades have even the slightest effect. And even if it were possible to achieve international cooperation, which seems to be the lesson that Gaia is teaching us, even if it were possible to begin immediate implementation of the soundest building practices: enduring cities, load bearing masonry, modest use of wood; even if it were possible to develop the soundest forms of transport that did not require fossil fuels; even if it were possible to realize these improvements tomorrow, it will take many centuries for the Earth to respond to the effects. We simply have to learn the wisdom derived from our mistakes. In other words, to adapt to conditions that are largely of our own making. And we seem to learn the best lessons following catastrophes.

\section{Nature and the City: a co-evolutionary project}

What is the role of architects in this condition? Architects, who are animated with the best of intentions will do their best when they can. Many become gleefully content for having reduced a building's carbon footprint with the full expectation that if they were to simply multiply this experiment, then they would have fulfilled their share in reducing global heating. Naturally, they do this with the full hope that every small advance helps, with the full hope that others are also genuinely engaged in achieving the same goals. Many architects also produce buildings with reduced carbon footprints while ignoring the exorbitant environmental effects of the materials that produce such buildings (the steel, the aluminum, the glass, the polyurethane, the bituminous tar, and the high transportation costs). Many architects and developers continue to waste resources and intelligence in order to build the same sprawling suburbia but with less toxic materials. Others architects, who ought to know better, pursue manifest contradictions such as "green skyscrapers". Not only did the skyscraper, overturn the clear hierarchy of civic and private buildings that characterized the traditional city, not only is the skyscraper an extreme concentration of people within a vertical cul-de-sac, not only is it the most pollutive building known to humanity, but it persists as the very icon of modernization - that elusive and delusive quality that is equally claimed by government officials and by developing nations who wish to emulate wealthier 
nations. Most flagrantly, the skyscraper, and other icons of modernization, came to be associated with the architects' furor to distinguish themselves as constructed dramatic figures who desire being applauded for the vast agglomerations of components that the technological society makes available.

At present, many architects employ themselves at serving the images of modernization at great ecological and urban costs. The ecological crisis has shown that we are and have been reaching certain limits to natural resources and urban resources. Yet many architects are unwilling to recognize contradiction between the urgent need to ecologize and the demands of omnivorous modernization. But this is a larger problem within modern culture itself - a corporate-dominated culture who refuses to make the choice between unbridled modernization and the planet's ecology. By placing their lot behind unbridled modernization, in their practice and in the education that prepares them for such practice, architects contribute to the general ecological and urban degradation that has been plaguing the planet.

By contrast, traditional architects have recoiled from the ecological and urban degradation and have been building solid and lasting masonry buildings and a limited use of wood as a rational strategy for long-term enduringness. But there simply are too few of them in comparison to the dominant planetary building and transportation practices. Much of what is currently called sustainable development is probably better described, as we mentioned, in James Lovelock's expression: sustainable retreat, a voluntary scaling down, a drawing back, a recoiling, from the detrimental practices we have been inflicting on the planet. This is a perfectly understandable reaction on the part of reasonable people retreating from the edge of the abyss. Beyond sustainability, beyond mere sustainable retreats, we can simultaneously develop the most enduring building practices possible for the sake of accommodating the probable massive migrations resulting from severe climatic conditions. An example of short-term sustainable practice, in this case, includes planning for new and smaller cities on higher ground, and here is where architects can play a significant role. For they can offer solutions to problems that can be reasonably predicted. This area of practice can be realized as a parallel path - one that offers a genuine choice between current building practices and enduring cities of stone.

In our collective evolution we have dwelt within two environments that have sheltered us, provided sustenance, and also endangered us. These environments are Nature and the City. In Nature we found ourselves in a milieu that was given, whereas we built the City as a physical and moral manifestation of our modes of collective dwelling. As we reflected upon our direct and potential relationships to these two environments, we appropriated natural laws and used natural and human-made products for the purpose of building the shelter, the house, the settlement, and eventually the city. For much of its history, human order either imitated the natural order, or opposed it; while much of our modes of dwelling, that is, architecture, agriculture, industry, derived from the movement between these two orders. With alternating emphases throughout our history, we have considered Nature as a subject and we have considered nature as an object. We have always considered the City as a project - ideally, a project for living together justly. But nature too can be considered as a project for living together justly. Since nature and the city are the two milieux that we know, we might consider both nature and the city as one enduring co-evolutionary project. This would be a convergence of many important contemporary currents - deep ecology, eco-feminism, traditional architecture - the logical conclusion of which might be called a co-evolutionary partnership between the natural and the human. A co-evolutionary partnership between the nature made and the human made. The co-evolutionary project implies that we assume the responsibility for caring for the entire bio-sphere, the hydro-sphere, and geo-sphere, the entire ecosystem, something that Nature did on our behalf. We can care for them as if we were Nature. We can conserve and maintain them, without however deluding ourselves into believing that we can actually mould the life of Earth in order to fit our economic will.

The co-evolutionary project assumes the furtherance of the very cultures that produced exemplary landscapes and cities in the past side by side with recent research and application in architecture and urbanism; cultural history; geo-engineering and the environmental sciences; as well as legal scholarship and public policy. But this project will not work if we considered it from a nationalist perspective. Sustainability and enduringness do not stop at borders -those imaginary lines along which some groups wish to build walls in order to separate "us" from "them", in order to demarcate identity from otherness. This co-evolutionary project operates on the basis of sharing; not only the benevolent welcoming of climate immigrants, but an equitable sharing of what the Earth offers.

A reader might consider the preceding remarks as a pessimistic outlook that leaves little room for resilience, for cheerfulness. But to put the discussion as an opposition between a would-be optimism and a 
would-be pessimism is a false categorization because most architects hold within themselves something of both. To construct, of course, is always a hopeful task: a hope to serve the larger common good, and a hope to see one's ideas realized within that larger good. Hope always concerns short-term endeavors in comparison to long-term conditions. To construct good cities and load-bearing buildings today is an admirable task, but this task has to be assessed with respect to its long-term ecological effects. And herein lies the pessimism for the short term. Our collective situation is not unlike that of a man who has abused his body for decades, but who has suddenly decided to reverse course and begin to care for his body according to the healthiest practices available. This development is, without a doubt, encouraging, constructive, and welcome. But it will not stop the effects of decades of harmful living. Rather than classifying ourselves as optimists or as pessimists, we may consider ourselves as hopeful realists, in the sense of accepting the collective responsibility, the collective consequences for our common effects on the planet and our deep hope to one day achieve that ever-desired and ever-elusive balance for the Earth. Hopeful realists find both optimism and pessimism to be very useful adjusters of humanity's collective actions because when that hopeful day will arrive it will be after centuries of suffering on the part of all the species as well as the Earth herself.

Within the current maelstrom of climatic change, of shifting tectonic plates, of economic upheavals, of land grab and diminishing resources, and the urgent need for enduring building and enduring agriculture, an absurd idea is fortunately dying out: the idea that we as a species stand separate from the Earth. It is being replaced by the idea of dwelling wisely on this planet, an idea that requires nothing short of a global cooperation that endures for centuries. And that is welcome development.

\section{References}

Intergovernmental Panel on Climate Change. 2001. Third Assessment Report, Climate Change. Cambridge.

Kump, L.; Kasting, J.; Crane, R. 2004. The Earth system. New Jersey: Prentice Hall.

Lovelock, J. 1979. Gaia: a new look at life on Earth. Oxford.

Lovelock, J. 2006. The revenge of Gaia. Allen Lane.

Lovelock, J. 2009. The vanishing face of Gaia. Allen Lane.

Margulis, L. 1998. The symbiotic planet. London: Phoenix Press.

McKibben, B. 2010. Eaarth: making a life on a tough new planet. Henry Holt \& Co.
Millenium Ecosystem Assessment Report. 2005. Washington, DC: Island Press.

Shiva, V. 2005. Earth democracy: justice sustainability and peace. South End Press.

Shiva, V. 2010. Staying alive. South End Press.

Wilson, E. O. 1998. Consilience. Vintage.

\section{SAMIR YOUNÉS}

Professor of Architecture at School of Architecture, University of Notre Dame, 110 Bond Hall, Notre Dame, Indiana, 46556, USA. E-mail:samir.younes.1@nd.edu

His most recent book is titled The Imperfect City: On Architectural Judgment. 